\title{
PROCEDIMENTOS OPERACIONAIS NO PÁTIO DE MINÉRIOS DURANTE PERIODOS DE FORTES CHUVAS*
}

\author{
Antonio Regio Avancini ${ }^{1}$ \\ FlavioTulio Busatto ${ }^{2}$ \\ Hugo Guimarães Menezes ${ }^{3}$ \\ Janaina Volpe Armacollo 4 \\ Jose Antonio Perez Alonso ${ }^{5}$ \\ Magno Domingos Garcia ${ }^{6}$ \\ Rinaldo Henrique Pedrini ${ }^{7}$
}

\section{Resumo}

Nos últimos anos Vitória vem sendo fortemente afetada por chuvas torrenciais em um curto período de tempo. Para garantir a segurança dos trabalhadores e equipamentos como também reestabelecer as condições normais de trabalho num menor intervalo de tempo, foi necessário rever e criar alguns procedimentos com o intuito de mitigar o efeito das chuvas. Os procedimentos são voltados principalmente a melhor manutenção das galerias de escoamento de água, melhorias no sistema de drenagem dos pátios, redução de altura das pilhas de matérias-primas, melhorias nos procedimentos de recuperação das matérias-primas dos pátios.

Palavras-chave: ArcelorMittal Tubarão; Sinterização; Chuvas; Pátio de minérios.

\section{Abstract}

\section{HANDLING PROCEDURES DURING HEAVY RAIN SEASON}

In the last years Vitória has been strongly affect by the heavy rains in a short period of time. In order to assure the safety of workers and equipment and to reestablish the normal production in a shorter time, it has been created some new procedures and modified some others to mitigate the consequences of the heavy rains. The mains goals of these procedures are: improve maintenance in the drainage system; reduction the pile height in the stock yard; improvement in procedures to recovery the raw materials.

Keywords: ArcelorMittal Tubarão; Sinter plant; Rains; Iron ore stock yard.

1 Engenheiro Metalúrgico, Especialista de Controle Técnico de Processo da Sinterização, Área de Controle de Produção da Sinterização, ArcelorMittal Tubarão, Serra, ES, Brasil.

2 Engenheiro Metalúrgico, Especialista de Controle Técnico de Processo da Sinterização, Área de Controle de Produção da Sinterização, ArcelorMittal Tubarão, Serra, ES, Brasil.

3 Engenheiro Metalúrgico, Especialista de Controle Técnico de Processo da Sinterização, Área de Controle de Produção da Sinterização, ArcelorMittal Tubarão, Serra, ES, Brasil.

4 Engenheira Química, Especialista de Controle Técnico de Processo da Sinterização, Área de Controle de Produção da Sinterização, ArcelorMittal Tubarão, Serra, ES, Brasil.

5 Contador, Supervisor de Controle Técnico de Processo da Sinterização, Área de Controle de Produção da Sinterização, ArcelorMittal Tubarão, Serra, ES, Brasil.

6 Administrador de Empresas, Técnico de Controle Técnico de Processo da Sinterização, Área de Controle de Produção da Sinterização, ArcelorMittal Tubarão, Serra, ES, Brasil.

7 Engenheiro Metalúrgico, Gerente de Operação de Sinterização e Patio de Matérias Primas, ArcelorMittal Tubarão, Serra, ES, Brasil. 


\section{INTRODUÇÃO}

Nos últimos anos o Espirito Santo tem sido surpreendido por chuvas torrenciais em um curto período de tempo. O período chuvoso na região do Espirito Santo concentra-se no período de outubro a janeiro como também em março e abril (pelo novo gráfico a ser inserido). Neste período a média do índice pluviométrico chega a ser até o triplo da média de alguns meses do período de seca (inverno). A média anual de chuvas para a cidade de Vitória oscila entre 1250 1350 mm.

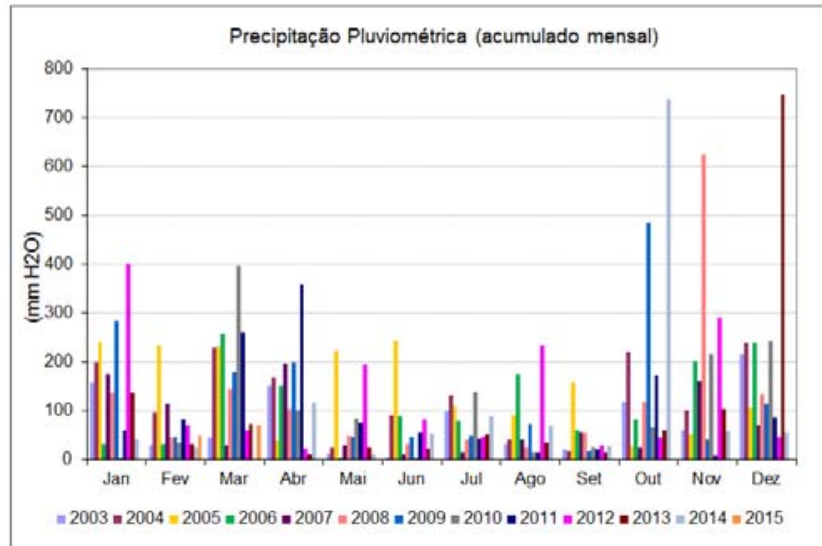

Fig.1 - Precipitação pluviométrica (dados de Grande Vitória) - 2003 a 2015

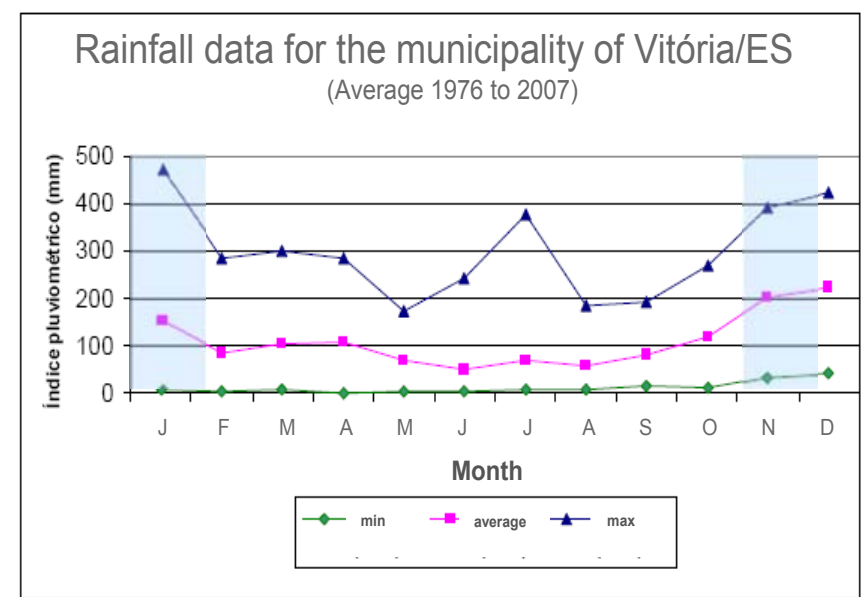

Fig.2 - Índice Pluviométrico do município de Vitória - ES (média de 1976 a 2007).

Por se tratar de grandes quantidades de água em pouco tempo alguns procedimentos operacionais tiveram que ser criados outros revisados. Esses procedimentos visam evitar os riscos de segurança as pessoas e equipamentos, como também reestabelecer as condições normais de trabalho num menor intervalo de tempo.

Os procedimentos são voltados principalmente a melhor manutenção das galerias de escoamento de água, melhorias no sistema de drenagem dos pátios, redução de altura das pilhas de matérias primas, melhorias nos procedimentos de recuperação das matérias-primas dos pátios, controle da distância entre as pilhas nos pátios primários, e ainda de aplicação de supressores / polímeros para evitar os desmoronamentos das pilhas. 


\section{DESENVOLVIMENTO}

\subsection{Precipitações de Março de 2013}

Em março de 2013 a região de Vitória teve uma grande concentração de chuvas. As chuvas trouxeram inúmeras consequências à população. $O$ índice pluviométrico foi de $128 \mathrm{~mm}$ em $36 \mathrm{~h}$.

$\mathrm{Na}$ região industrial, as chuvas também trouxeram consequências para a ArcelorMittal e teve um impacto significativo desde o recebimento de minérios via ferrovia (interrupção de trechos da Estrada de Ferro Vitória Minas) quanto para o processo de estocagem, manuseio e também à produção e qualidade do sínter.

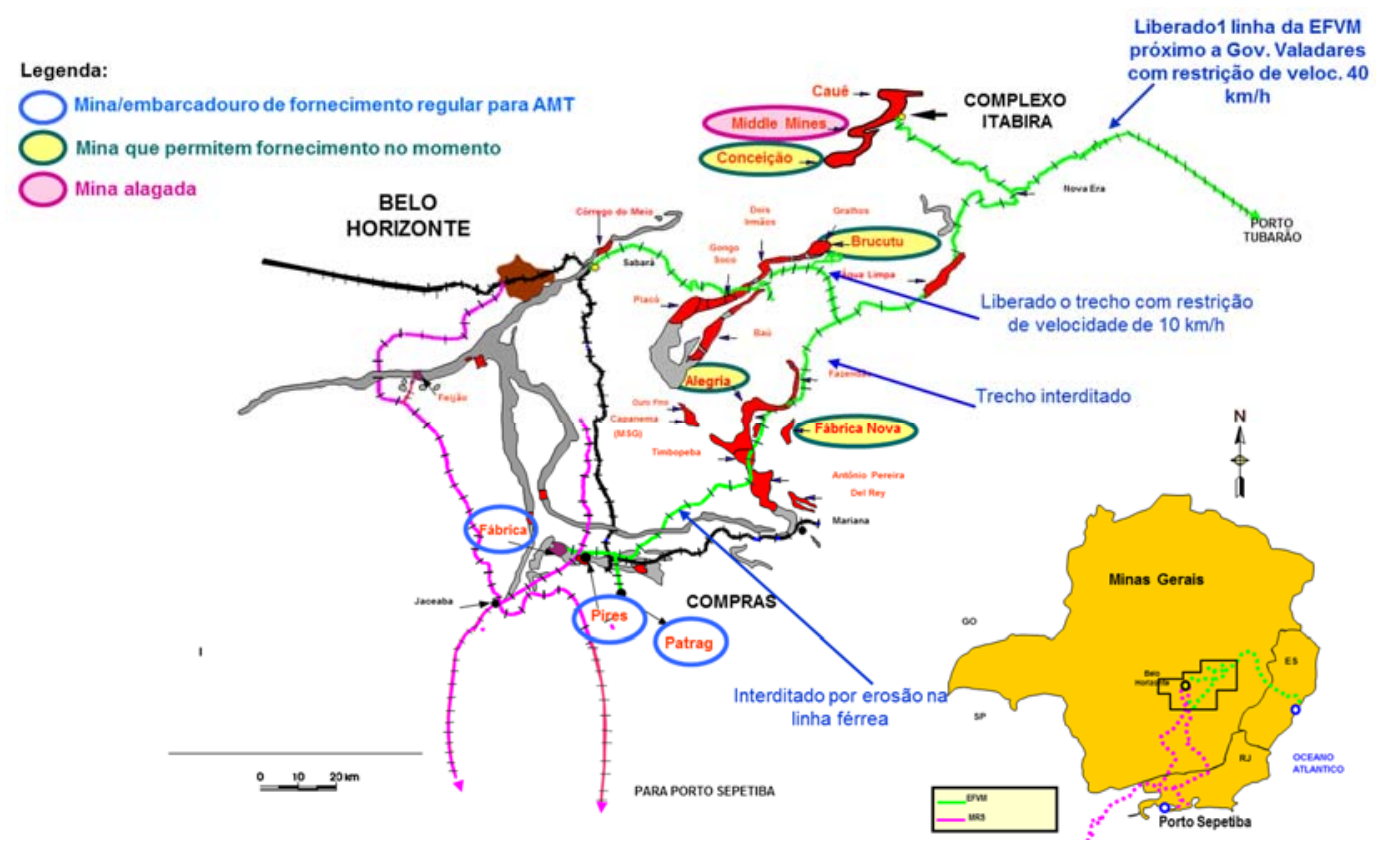

Fig. 3 - Exemplo de uma condição da EFVM durante período de chuvas intensas.
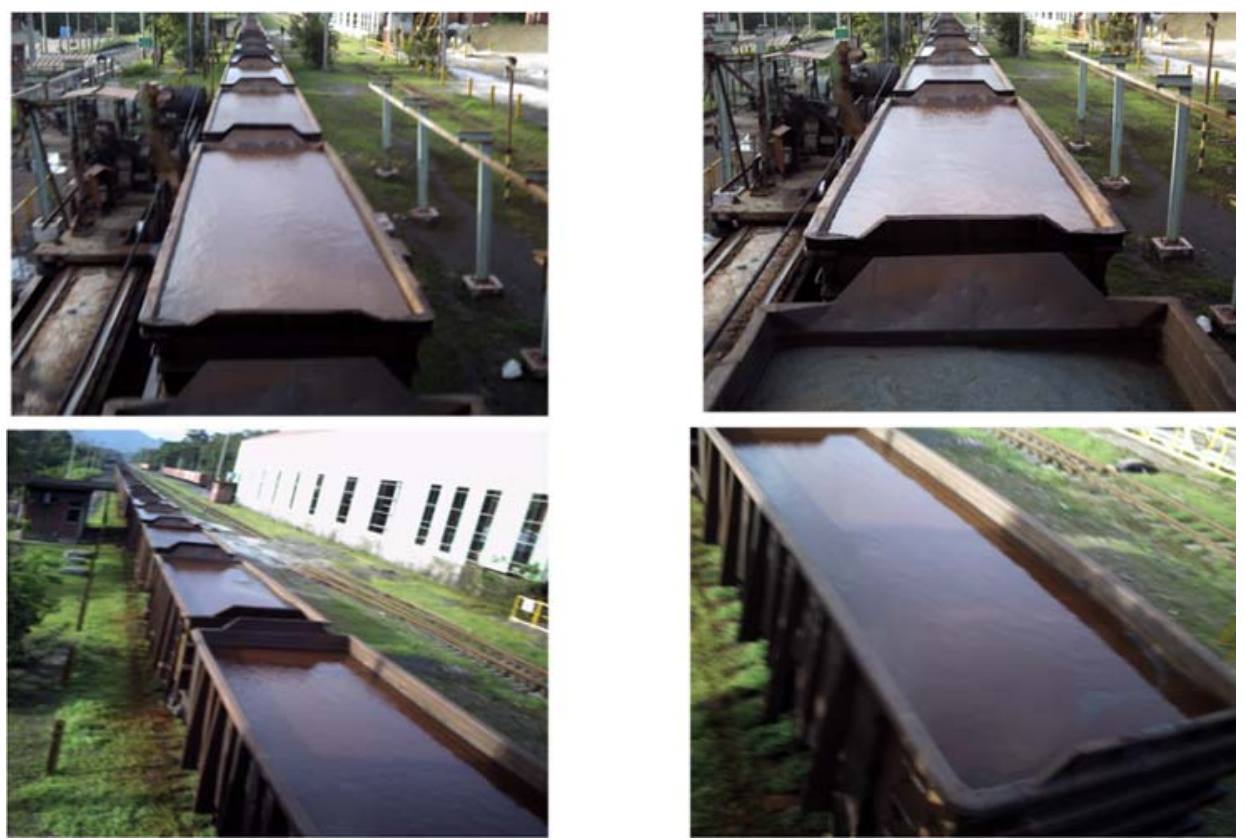

Fig.4 - Condição de recebimento de lotes de minérios finos, o qual não conseguiu ser descarregado, sendo necessário interromper a descarga por questões de segurança. 


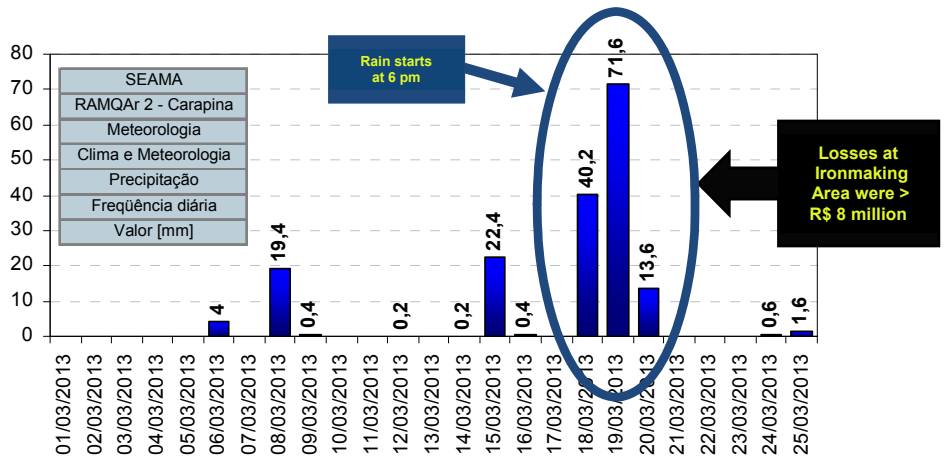

Fig. 5 - Precipitação pluviométrica na Grande Vitória no período de março e 2013.

Devido a esses impactos em março de 2013 um plano de contingencia para períodos chuvosos foi implementado na ArcelorMittal Tubarão cujo objetivo é mitigar e garantir a operação da planta em condições seguras para os trabalhadores e equipamentos.

\subsection{Principais Ações Realizadas}

\subsubsection{Revisar os procedimentos operacionais}

Visando minimizar e/ou eliminar os efeitos das fortes chuvas (foco na manutenção de cobertura de correias transportadoras, limpeza, alinhamento de correias, limpeza de calhas de transferências, bombas e etc.).

\subsubsection{Redução do tamanho das pilhas durante o período chuvoso (Novembro a março)}

Redução de 150kt para 100kt (pilha de homogeneização) para minimizar o risco de arriamentos/desmoronamentos.

\subsubsection{Manutenção do sistema de drenagem dos pátios de homogeneização e matérias-primas e propostas de melhorias}

Evitar acúmulo de materiais que possam obstruir a passagem de água.

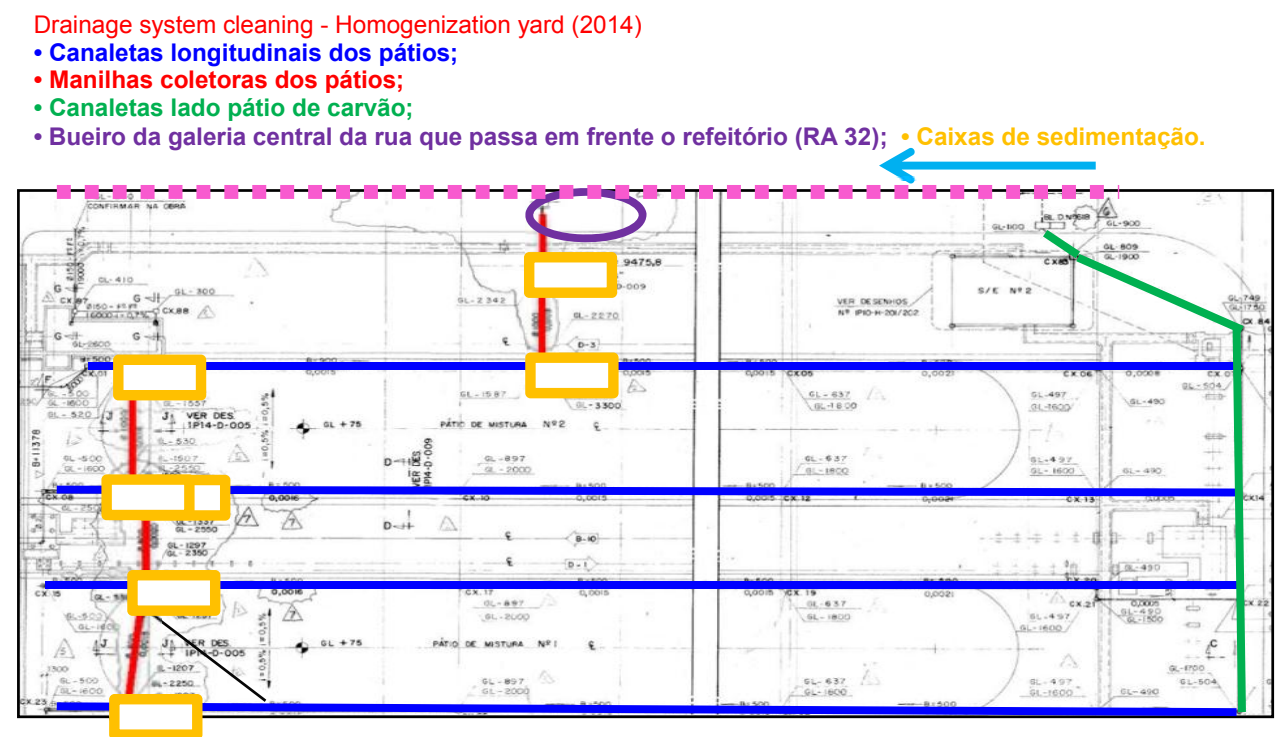

Fig. 6 - Canaletas pátio de minérios. 
2.2.4 Estudos de melhorias com o objetivo de proteger ou enclausurar as pilhas

Aplicação de polímeros na superfície das pilhas para evitar arriamentos devido à infiltração de água. Também há um ganho em paralelo onde é possível de evitar arraste eólico e reduz o consumo de água para aspersão.
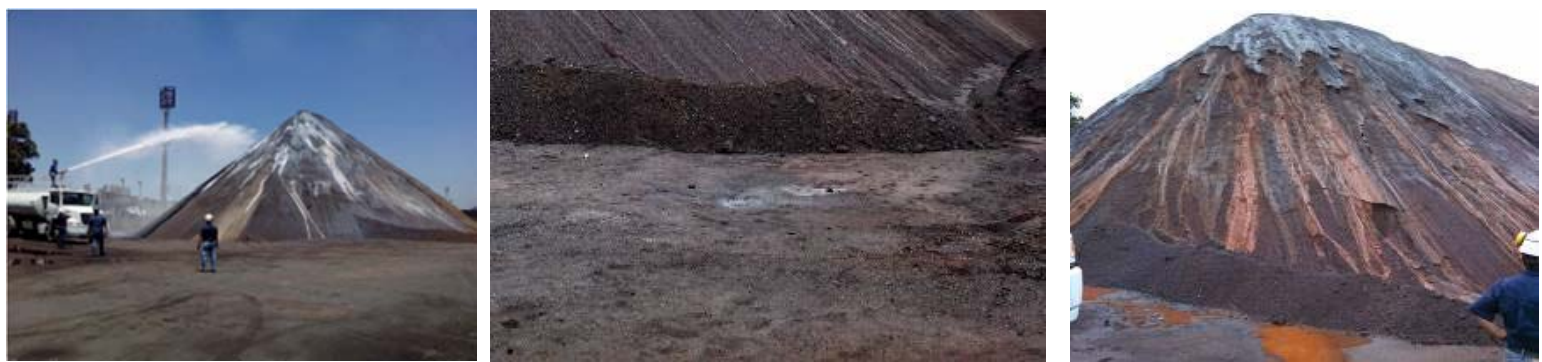

Fig. 7 - Aplicação de polímeros na pilha a fim de criar uma película protetora e minimizar os efeitos da chuva.

\subsubsection{Criação de procedimentos de inspeção de pilhas}

Inspeções visuais com o objetivo de detectar erosões ou alta umidade para tomar ações preventivamente.

\subsubsection{Desenvolvimento de um estudo de benchmarking com outras usinas do grupo Usinas consultadas: Gent, Dunkerque, Dofasco and Indiana Harbor}

\subsubsection{Manter a distancia segura entre as pilhas e as muretas de contenção}

Objetivo de não correr o risco de o material parar em cima dos trilhos das maquinas do pátio dificultando assim a remoção.

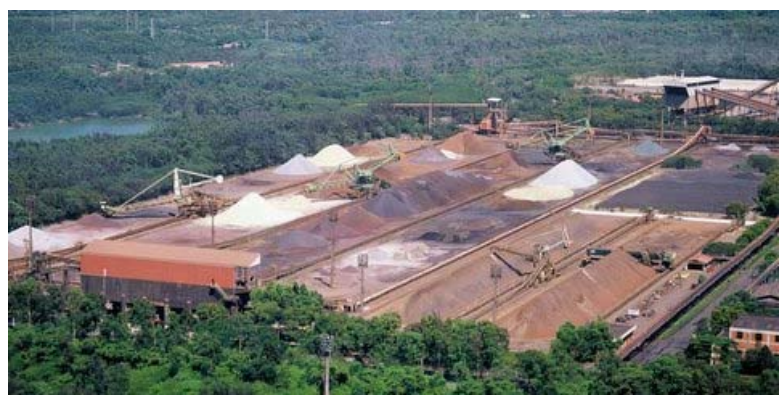

Fig. 8 - Vista do pátio de minérios.

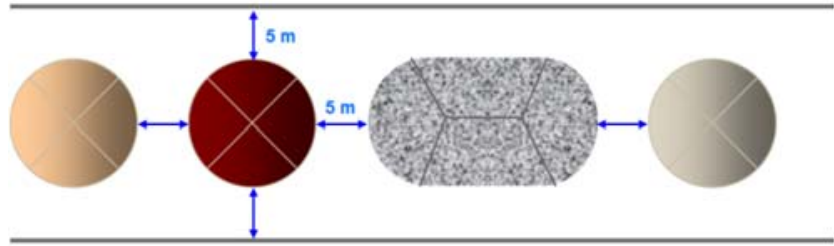

Fig. 9 - Distancias entre pilhas no pátio de minérios. 


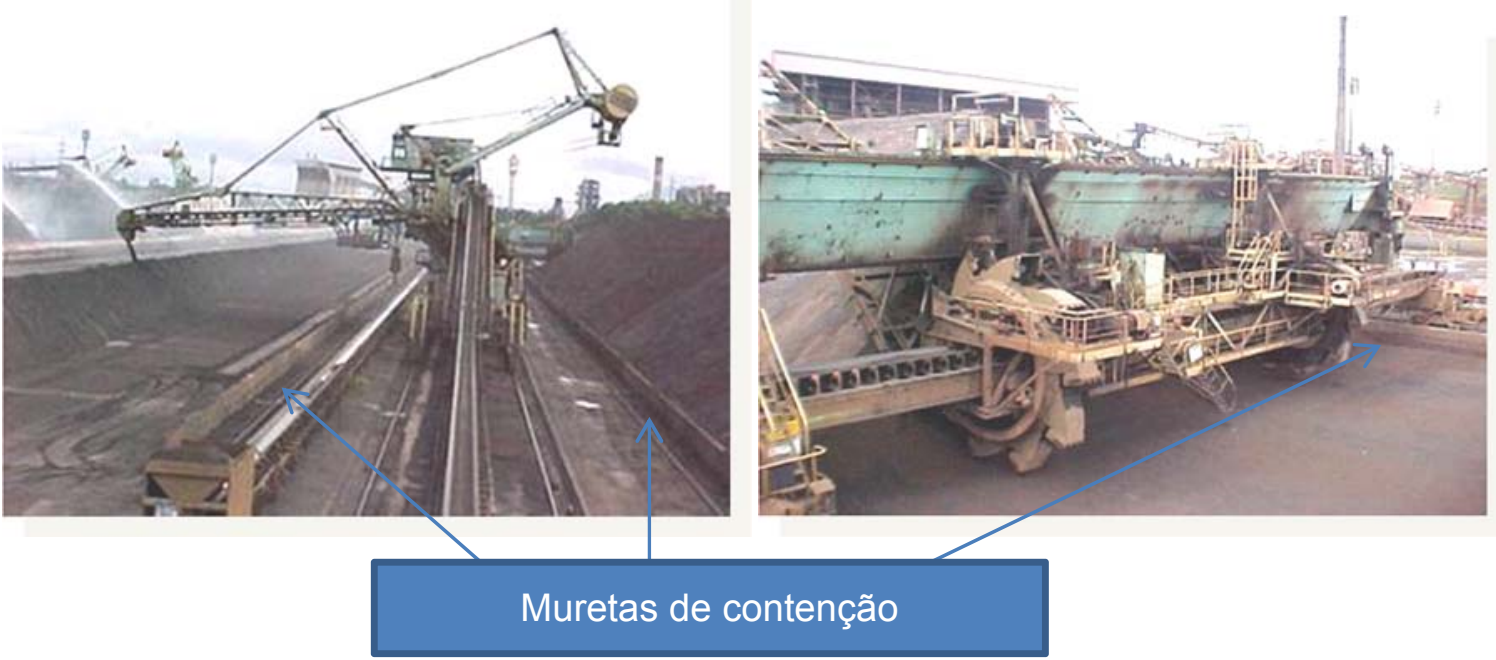

Fig. 10 - Pátio da blendagem e muretas de contenção.

2.2.8 Intensificar a inspeção de bombas, scrapers, vibradores de silos, calhas, peneiras, sistemas de drenagens dos canais, bacia de decantação e etc.

Evitar acúmulo de materiais que possam obstruir a passagem das matérias-primas e drenagem de água.

2.2.9 Contingenciar bombas extras em períodos chuvosos.

Ajudar na drenagem de água de locais estratégicos.

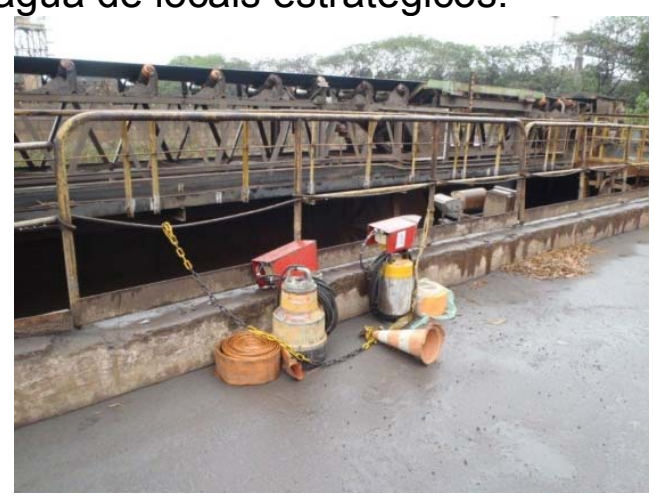

Fig.11 - Bombas Reservas.

2.2.10 Ajustar o mix de combustível (priorizar o consumo de coque ao invés de antracito)

O coque é de mais fácil manuseio quando úmido se comparado ao antracito.

\subsubsection{Durante chuvas fortes paralisar a recuperação de pilha homogeneizada para a sinterização \\ Para evitar acumulo de material e água na cauda das correias com inclinação.}

2.2.12 Reduzir a vazão de materiais nas correias transportadoras $(\downarrow t / h)$ para assegurar a qualidade para os altos fornos e a estabilidade das correias

A umidade elevada afeta diretamente o peso dos materiais sobre as correias tendo um risco maior de desalinhamentos, travamentos de rolos, transbordamento de material e etc. 


\subsubsection{Equipe especifica de contingencia para limpeza de área}

Ações preventivas com o intuito de evitar acúmulo de materiais que dificultariam o escoamento da água como por exemplo a retirada de material que sofreu erosão das pilhas após a ocorrência de chuvas.

\subsection{Precipitações de Dezembro de 2013}

Em dezembro de 2013 as chuvas novamente castigaram Vitoria. As chuvas representaram mais de $50 \%$ da precipitação esperada para o ano todo. A cidade sofreu fortes impactos 30 pessoas morreram e mais de 48.000 pessoas perderam suas casas e ficaram desabrigadas.

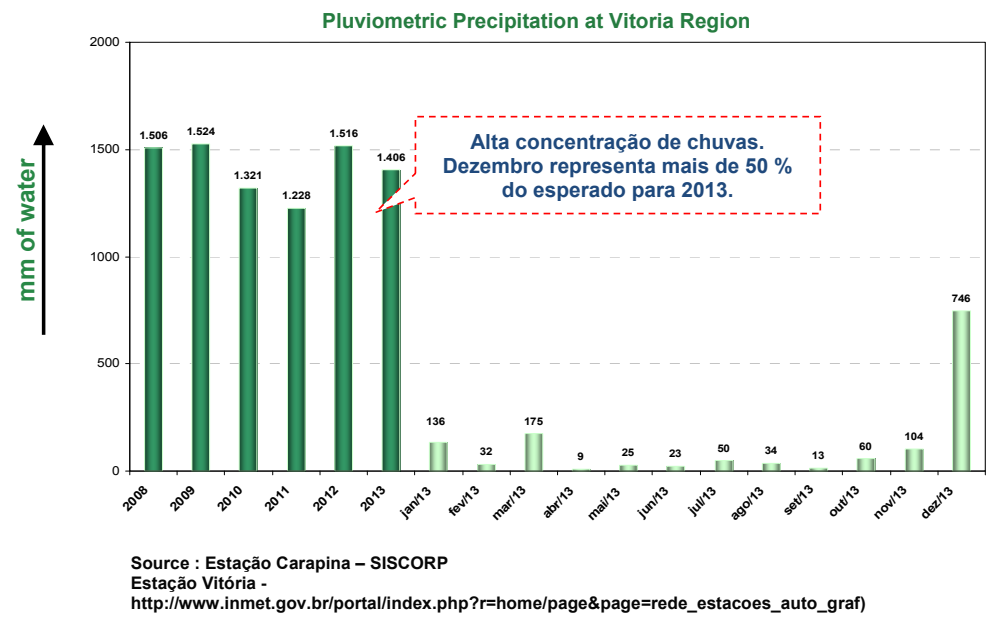

Fig. 12 - Precipitação Pluviométrica na Grande Vitória no ano de 2013.

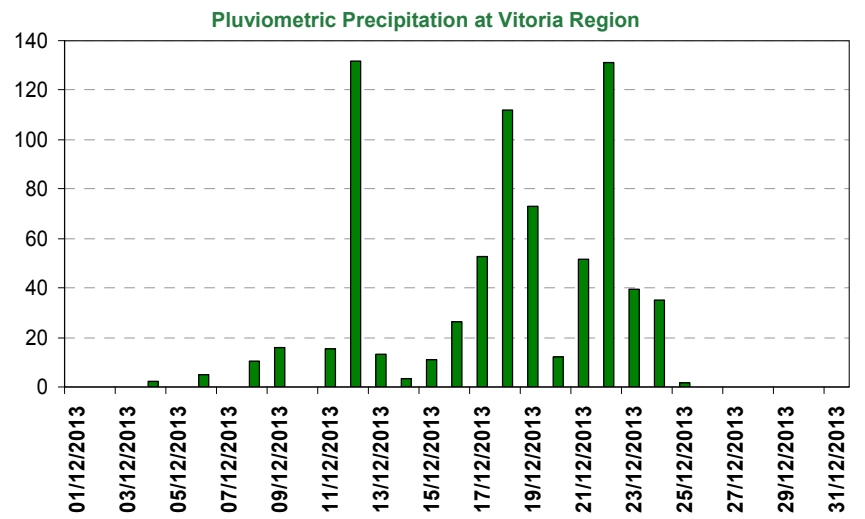

Fig. 13 - Precipitação Pluviométrica na Grande Vitória em dezembro de 2013.

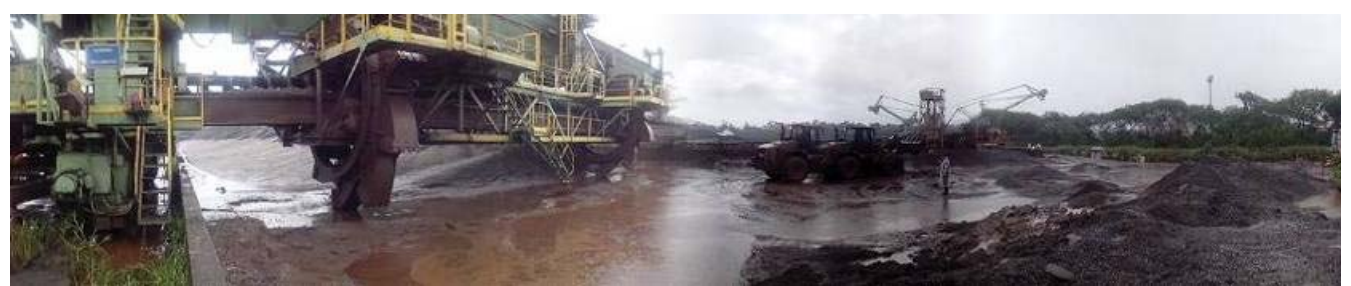

Fig.14 - Equipamento Blending Reclaimer - Água acumulada no pé da pilha de homogeneização. 


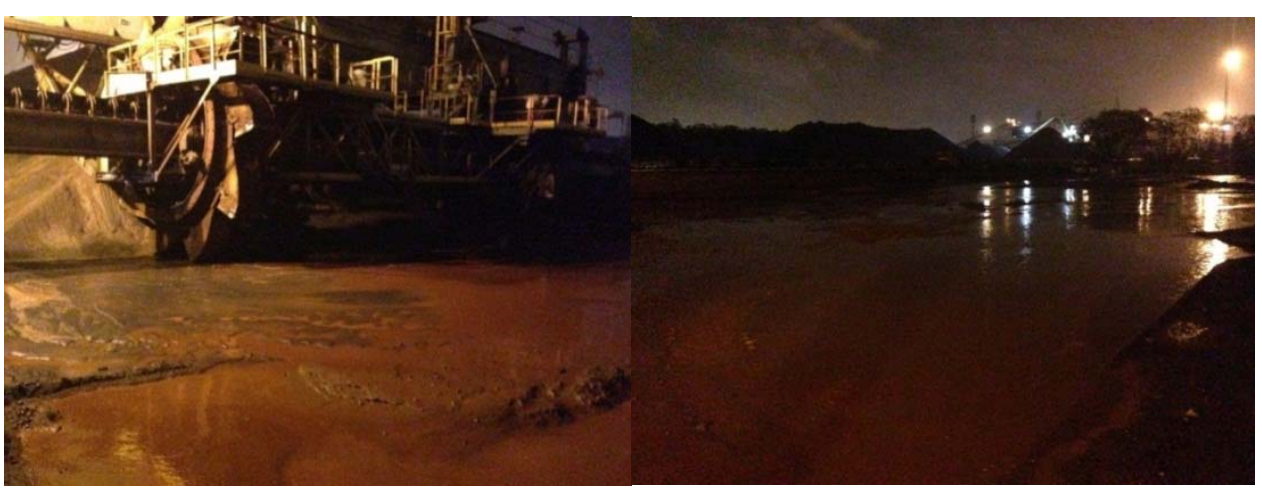

Fig.15 - Pátio de Homogeneização.

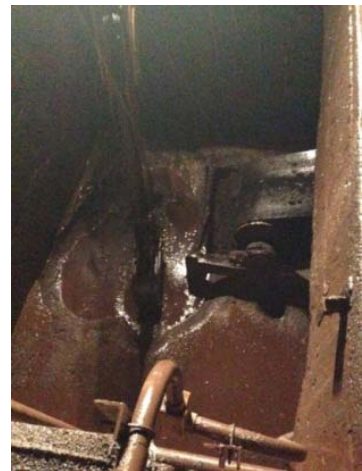

Fig. 16 - Cauda da Correia Transportadora D4 (envio de matéria prima para Sinterização). Acúmulo de água.

Com as ações implementadas em março de 2013 foi possível minimizar os impactos das fortes chuvas no mês de dezembro 2013. As perdas de produção e os riscos operacionais foram mitigados, no entanto ainda houve perdas significativas (alagamentos no pátio de minério e blendagem, entupimentos de calhas, falta de bombas para drenagem de pontos estratégicos).

\subsection{Precipitações de Outubro de 2014}

A Grande Vitória foi fortemente impactada por conta da forte chuva que caiu no dia 30 de outubro. De acordo com a Defesa Civil Estadual, a Serra foi o município mais castigado, município no qual se encontra a usina ArcelorMittal Tubarão. Na cidade houve casas que desabaram e inúmeras pessoas desabrigadas.

Em um dia choveu mais que $300 \mathrm{~mm}$ que é o equivalente de 2 a 3 meses (período chuvoso). Porém, especificamente no bairro Novo Horizonte onde está situada a ArcelorMittal Tubarão choveu em 7 horas cerca de $738 \mathrm{~mm}$ o que seria equivalente a cerca de 6 meses do ano. 


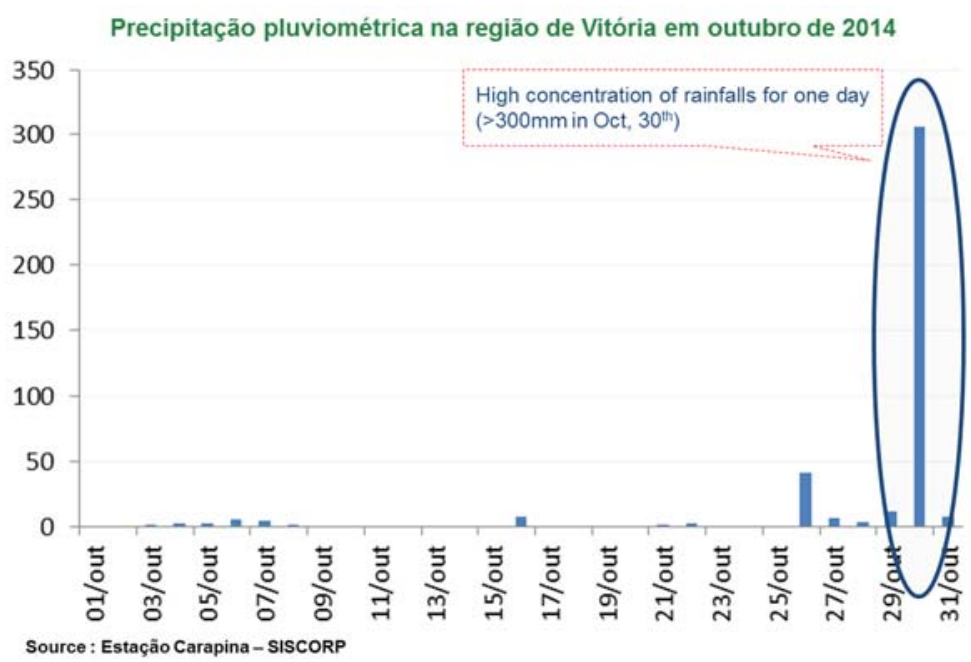

Fig.17 - Precipitação Pluviométrica na Grande Vitória em outubro de 2014.

Mesmo com toda a chuva deste período os prejuízos foram mínimos. A produção de sínter não foi afetada diretamente e não houve prejuízos de equipamentos, minimizado também alagamentos e facilitado à drenagem por ter bombas disponíveis para tomada de ação imediata.

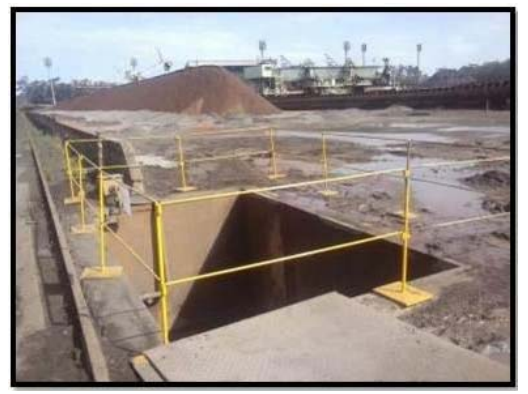

Fig. 18 - Pátio da Blendagem e poço da D4.

\section{CONCLUSÕES}

As ações implementadas nos meses de março e dezembro se mostraram eficazes. As consequências das chuvas de outubro de 2014 foram minimizadas, garantindo a segurança dos trabalhadores e equipamentos. As perdas de produção foram mitigadas e o retorno da produção foi realizado em menor tempo se comparado aos outros períodos chuvosos.

\section{BIBLIOGRAFIA}

1. Instituto Capixaba de Pesquisa, Assistência Técnica e Extensão Rural [pagina da internet - acesso em 02/04/2015]. Disponível em: http://www.incaper.es.gov.br

2. GE Water \& Process Technologies - Disponível em:

http://www.gewater.com/pt/index.jsp

3. Nalco na Ecolab Company - acesso em 30/3/2015. Disponível em: http://ptla.nalco.com/la/

4. Lima, A. B. T. Aplicações de cargas minerais em polímeros, Escola politécnica da Universidade de São Paulo - Departamento de Engenharia de Minas e de Petróleo, 2007.

5. Perdigão, José Ribamar Costa; Ferreira ,Paulo Fernando Mainente; Brandão, Eliezer de Jesus. Redutor de Umidade de Minério de Ferro. Disponível em: 
http://www.revistaferroviaria.com.br/premios/EDLP2011/Redutor-de-Umidade-deMinerio-de-Ferro-Asper-1000-Reducing.pdf

6. Guachalla, Fabio Willam; Alcantara, Marcio; Candido, Anderson; Cota, Jose; Rodrigues, Fatima et al. Manuseio de Minério no Periodo Chuvoso. Disponível em:

http://www.otmeditora.com.br/encontrodeferrovias/hd/arquivos/a80bcf922a.pdf 